\title{
DEVELOPMENT OF A HYBRID MACHINE LASER ENGRAVING AND ROUTING
}

\section{KARIME HERNÁNDEZ GEGEN ${ }^{1}$, GUSTAVO A. RAVE RÍOS², ALBERT MIYER SUAREZ ${ }^{3}$ \& SIR- ALEXCI SUAREZ ${ }^{4}$}

1, 2, 3 Engineering Faculty. University of Pamplona, Colombia

${ }^{4}$ Engineering Faculty, University Francisco of Paula Santander Ocaña, Colombia

\begin{abstract}
Recognizing the evolution of numerical control and its application in desktop and industrial equipment, the construction of small machines has been proposed to support the academy. Through this writing, the development of a hybrid CNC machine is shown that allows a router to be operated together with a laser engraving tool; in turn, a safety system has been designed to protect the operator. On the other hand, the basic electronics required for the respective configuration are shown, obtaining a robust and multifunctional desktop computer.
\end{abstract}

KEYWORDS: CNC, CAD, Hybrid Machine, Ruter, Laser

Received: Oct 06, 2020; Accepted: Oct 26, 2020; Published: Nov 30, 2020; Paper Id.: IJMPERDOCT202073

\section{INTRODUCTION}

During the 21 st century, technological advancement has grown exponentially, achieving multiple developments in research, among these developments is the increase in computational power, where in 1947 the first computer had a dimension of $2.6 \mathrm{mx} 0.9 \mathrm{mx} 24 \mathrm{~m}$ and a weight of 27 tons, currently the smallest computer measures only $0.3 \mathrm{~mm}$ from side to side including ram memory, processor, transmitters and wireless receivers.

Linked to computational evolutions is the computational numerical control for its acronym in English CNC that has gone from the handling of perforated paper tapes for the coding of the program, to the handling of design and manufacturing systems, controlling and monitoring the movements of a machine tool (Hernández et al., 2014).

The laser is the technology that began with Albert Einstein at the beginning of the 20th century. The technology further evolved in 1960 when the first laser was built at Hughes Research Laboratories (History of Laser Technology | Es-Us Laser Materials Processing, nd). Currently the laser has different uses from the medical sector to the manufacturing industry, where through the laser material cuts or engravings can be made with high precision.

Desktop machines have been made for laser engraving or cutting where they apply the implementation of the CNC system in order to control between 2 to 3 axes of freedom on a laser module that varies between $1 \mathrm{~W}$ to 20W. For example, Paola León and her work group created a CNC machine for foam cutting (Leon et al., 2016) using commercially easily accessible materials and having the advantage that they could use free software so that the cost of it did not will rise.

Routers on the other hand have been one of the most widely used machines today, because they allow machining designs made by CAD software. In Latin America, especially, Colombia has started in the construction of desktop machines replicating industrial designs on a smaller scale, with the purpose of reducing price and starting 
in the world of CNC, as in the case of Miguel Riquelme García of the Polytechnic University of Cartagena where he designed and manufactured a 3-axis CNC milling machine for the machining of PCBs (printed circuit boards), achieving a solid and fully functional structure for their respective use (García \& Zamora, 2014).

Every day the presentation of printed circuits is necessary, both for education and for marketing. Linked to the increase in the production of these components, the construction of desktop milling machines has increased exponentially (Cubides et al., 2009). This type of development allows us to be at the forefront of large national and international industries, taking into account simple equipment, easily created or acquired and that are functional and in accordance with the design parameters.

Covering all the concepts of design and coding by computational means, the construction of a machine that implements the two structures mentioned above (laser engraving and Router) is proposed, the first purpose is to create desktop computers of an academic nature and in turn present the design of a low-cost hybrid machine.

\section{METHODOLOGY}

The methodology shown below is emphasized on the hardware of the hybrid router-laser machine.

\section{Design the hybrid machine using CAD software.}

For the design of the machine, various references were evaluated, studying their configurations and combining their potentials. The most relevant parts are highlighted below.

\section{Transmission}

The movement of the coordinate axes is a primary factor because this parameter will be responsible for moving the work tool, be it the router or the laser module. In the commercial sector, different types of transmission can be found as a sample (Santa et al., Nd).

Ball screw: This type of screw is characterized by having a very efficient advance in which the balls perform a tilting movement between the screw axis and the nut, as seen in figure 1 (Ball Screw | [THK || MEXICO], nd ).

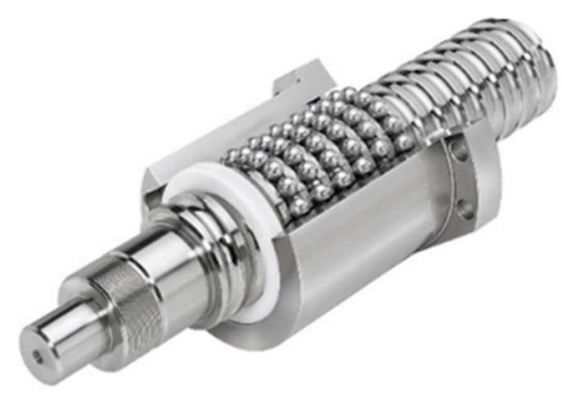

Figure 1: Ball screw transmission (Daza \& Luengas, 2016).

Trapezoidal spindle: This spindle is ideal for small CNC machines that do not need to make large movements. Compared to metric threaded rods, trapezoidal spindles have more precision and less clearance as shown in figure 2 (Trapezoidal Threaded Spindle TR8x1.5 | MakerShopBCN, nd). 


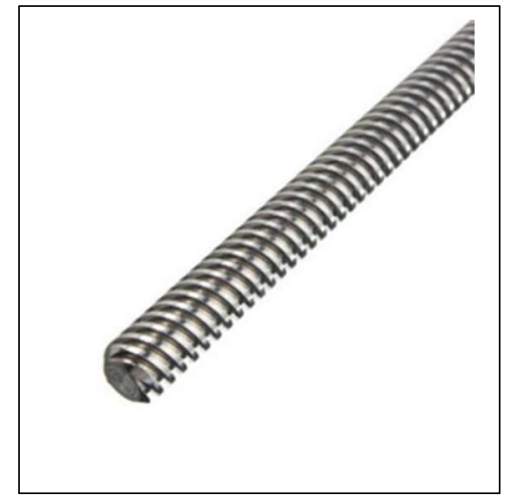

Figure 2: Trapezoidal spindle drive (Trapezoidal Threaded Spindle TR8x1.5 | MakerShopBCN, nd).

Belt transmission:The belts are power transmission elements, of flexible constitution as can be seen in figure 3, these are usually coupled on smooth or toothed pulleys. When it is required to transmit high power regimes, in transmissions that are compact, it is best to use toothed belts (Transmission Belts, nd).

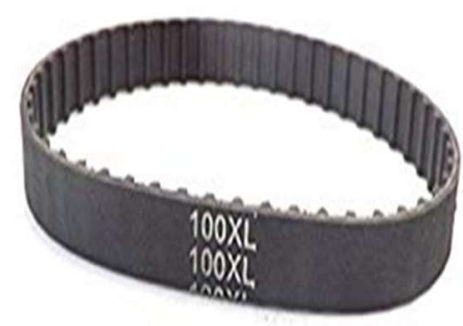

Figure 3: Belt transmission (Transmission Belts, nd).

\section{Structure}

The structure must contain all the necessary parts to interconnect the electronic part and the different components for the transmission of the machine axes. Nowadays, it is easy to have references to build a structure due to the different designs offered by the network. Proceeding with the search for references about how to build a structure for the machine, it was found that a 3-axis CNC milling machine was designed for PCB machining at the Polytechnic University of Cartagena, in figure 4 it can be seen that the elements necessary to give movement and control to the machine obtaining the following results.

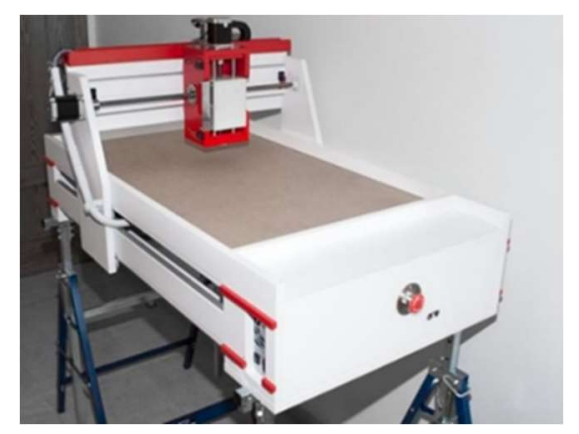

Figure 4: 3-axis CNC milling machine for PCB machining (García \& Zamora, 2014). 
Continuing with the research in Mexico City, a group of students developed a CNC Router for the elaboration of PCB boards, these people, as in the Polytechnic University of Cartagena, took into account the theory and the necessary components for its construction and thus develop the machine as shown in figure 5 (García \& Zamora, 2014).

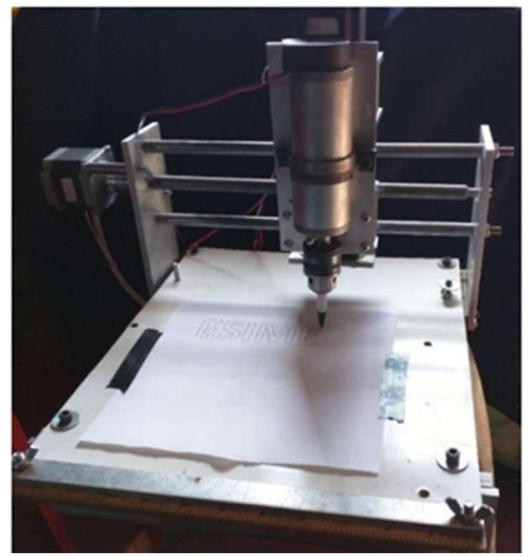

Figure 5: CNC router applied to the development of PCB's (Daza \& Luengas, 2016).

As can be seen in the figures described above, the structure they use is a bit complex and the components they use are expensive making the machine have a high cost, it was possible to find a machine developed in Spain by Mr. Ferrete as seen in Figure 6 this machine has parts made in 3D printing which minimizes the cost, another important factor is that it uses a belt transmission that differs from other types of transmission due to its price. When naming these advantages, it was decided to select this model in order to carry out a redesign and later incorporate the two necessary modules that are a router and a laser module (Daza \& Luengas, 2016).

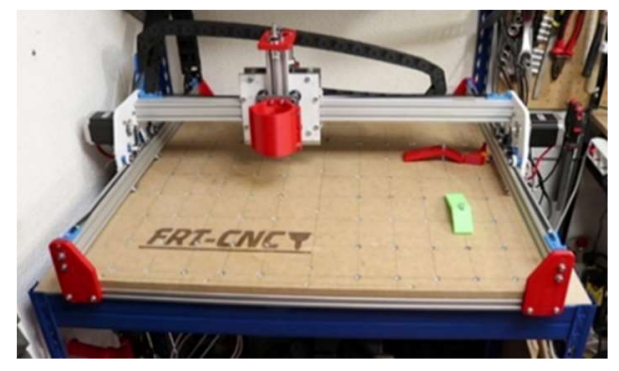

Figure 6: FRT- CNC (New Diy CNC - FRT_CNC- Finishing Assembly - La Web Del Mr. Ferrete, nd).

When selecting the model, we proceed with the construction of the CAD. For this research, SolidWorks 2018 software was used, being the one indicated due to its wide range of tools, allowing a complete design of the machine. The design procedure is shown below:

Sketch and Creation of 3D models: For the initiation of the sketch, the surface geometric measurements are taken into account, followed by the structure in an isometric plane of the solid in 3D where the finished model is displayed. In figure 7 and in figure 8 this first operation can be seen in the CAD elaboration process. 


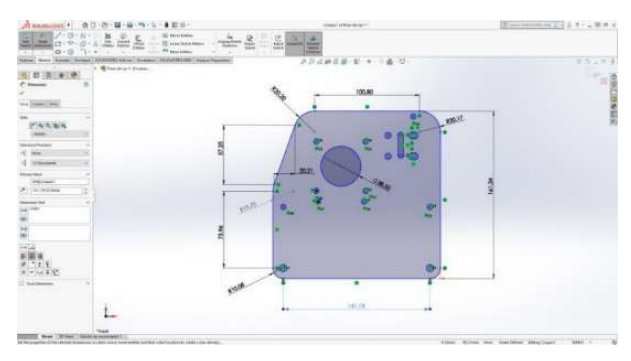

Figure 7: Sketch of the 3D model (Author).

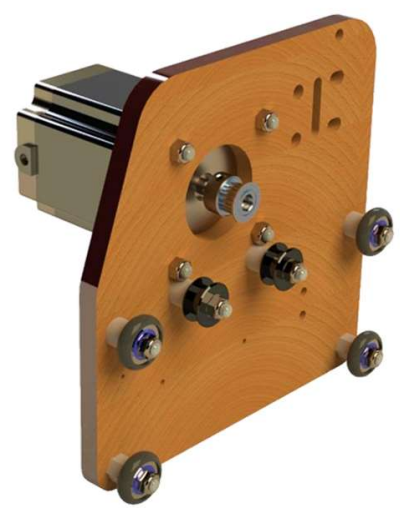

Figure 8: Y axis mechanism 3D model (Author).

Following the same methodology in the construction of all the mechanisms and parts necessary for the construction of the hybrid machine, figure 9 and figure 10 show the 3D model of the $\mathrm{X}$-axis and Z-axis mechanisms, which together with the mechanism of the $\mathrm{Y}$ axis will give the movement in the three coordinated axes through belt transmission. The topological analysis of the parts that make up the machine can be found in the publication by the same authors called "TOPOLOGICAL ANALYSIS APPLIED TO A CRITICAL PIECE OF A DESKTOP CNC MACHINE".

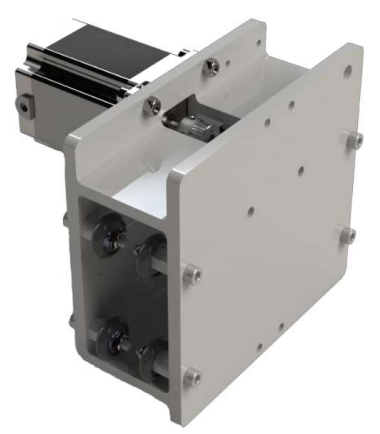

Figure 9: $\mathrm{X}$ axis mechanism 3D model (Author). 


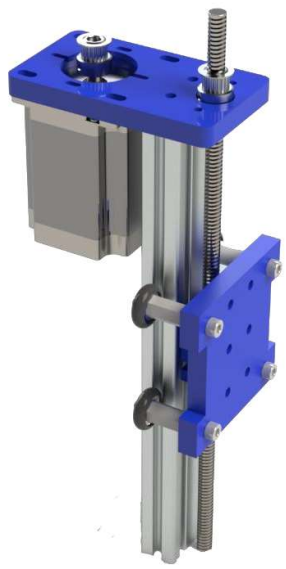

Figure 10: $\mathrm{Z}$ axis mechanism 3D model.

Once the three mechanisms have been completed with all the required sizing, the structural section is implemented that will protect the machine operator by providing stability to it. In figure 11 and figure 12 the complete design of the hybrid machine will be shown.

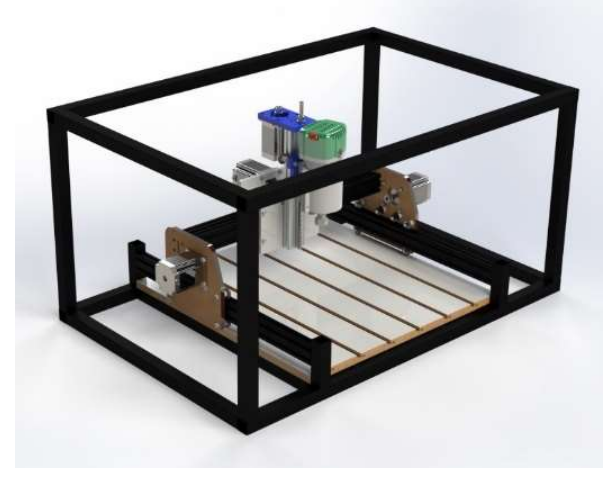

Figure 11: Hybrid machine with metallic structure.

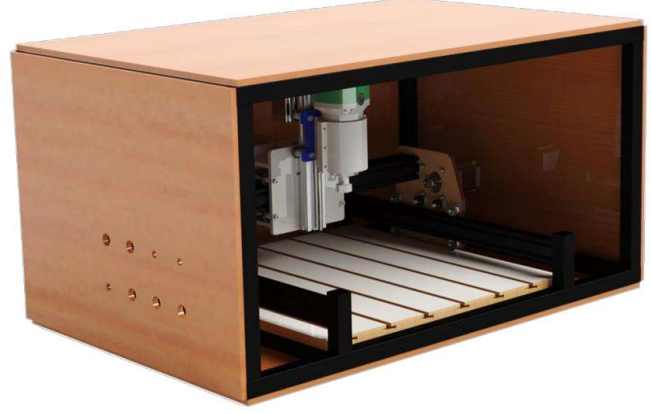

Figure 12: Hybrid machine complete design.

\section{Electronic Distribution}

During this section, the electronic distribution diagrams will be shown both for the respective movement of the motors, as well as for the operation of the $3.5 \mathrm{~W}$ laser and the Router. 


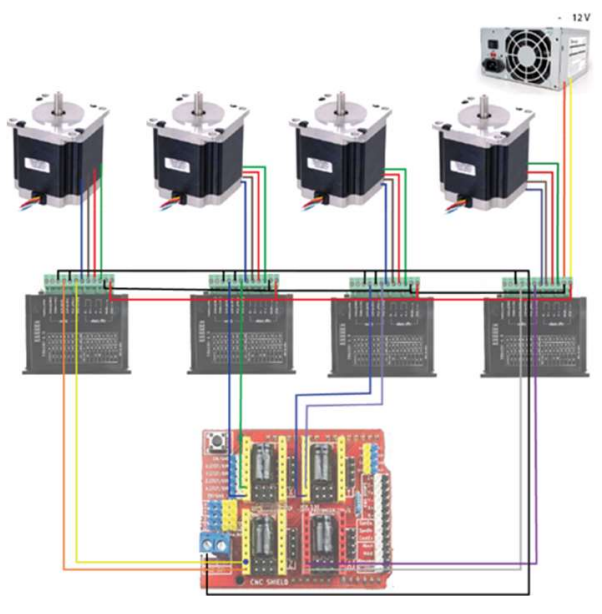

Figure 13: Connection diagram of electronic components.

Figure 13 shows the connection diagram of the stepper motors together with all the necessary components for their respective operation. This connection also fulfills the task of carrying out the respective communication between the computer and the machine, because initially the designs must be made and exported in G code so that they can be interpreted.

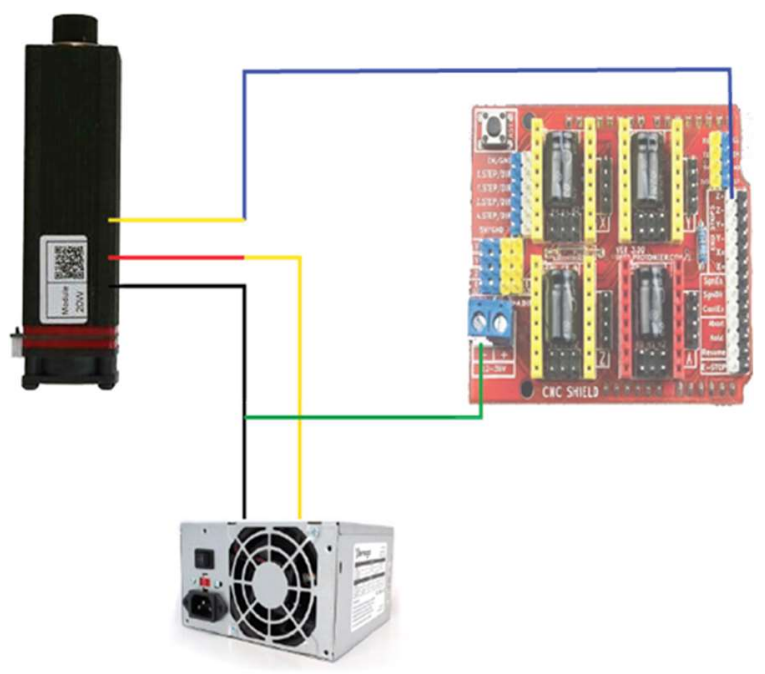

Figure 14: 3.5 W laser connection diagram.

Figure 14 shows the respective connection of the laser, this will be connected directly to the $12 \mathrm{~V}$ source in order to supply the necessary current without having inappropriate dips, it also shows the connection that it must have with the CNC Shield that will control the engraving power via PWM.

\section{Implementation of the Three-axis CNC Control System}

Figure 15 shows the procedure that happens internally before setting the machine to work, initially the G code of the part to be machined is created or, in the case of laser engraving, the design to be made. By having the code created, the file must be imported into the respective softwares in charge of interpreting each of the lines of code, and these programs are also in charge of configuring the machine before starting the project. 
At the time of starting the process, the software will be the transmitters of the information throughout the operation, sending signals to the electronics box that will be the receiver of all the information necessary to be able to give movement to the entire structure of the hybrid machine.

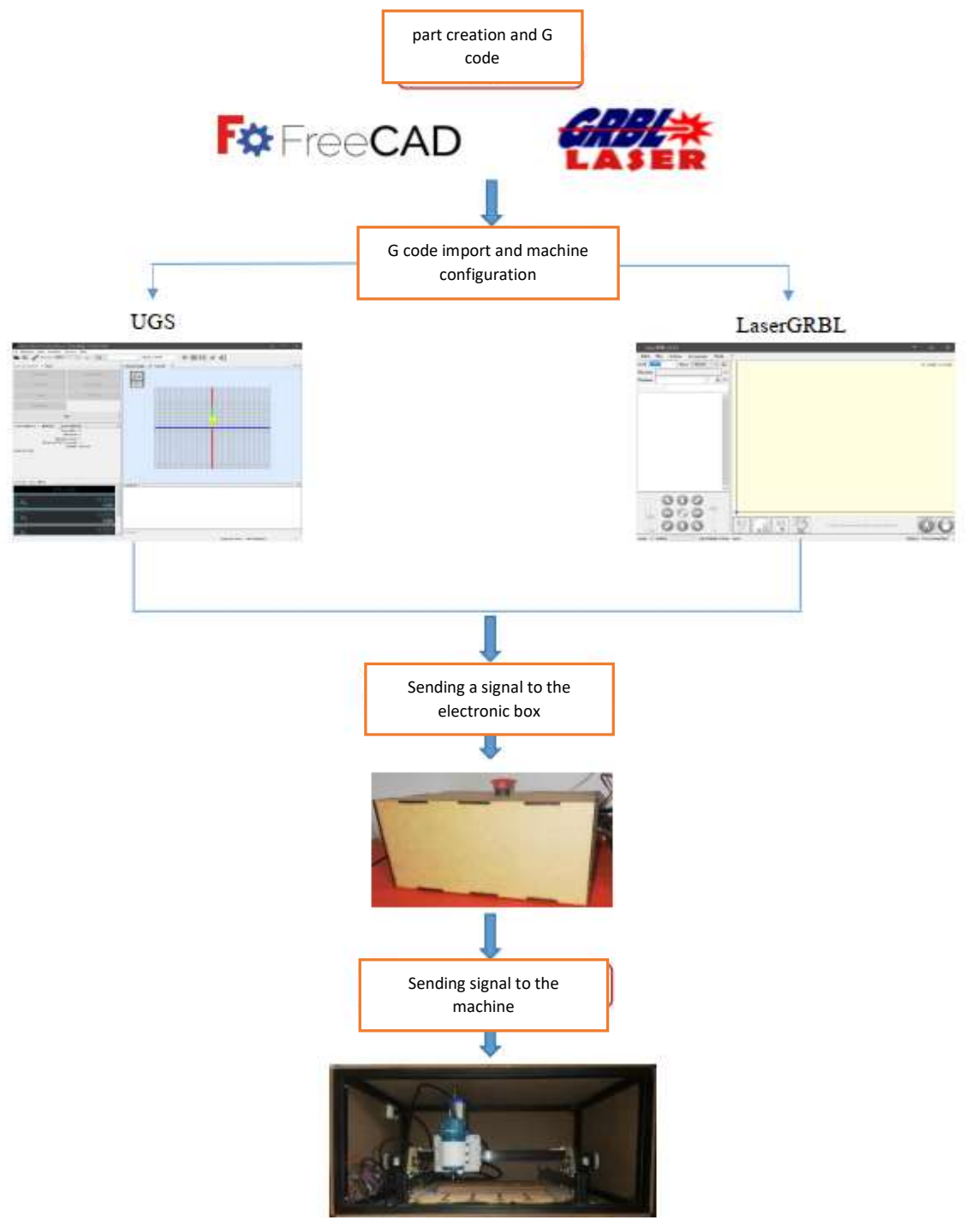

Figure 15: Control system procedure.

\section{RESULTS}

- The development of a hybrid machine allows a single structure to have two functional teams.

- The development of desktop computers provides economy and ease of use being accessible and affordable by more users

- The components that make up the machine are easily accessible, making their assembly simple.

- The components used in this design are low cost, but efficient, that makes it possible to replace any part that requires it.

- The use of free software also provides significant savings in this development, helping to reduce the overall costs of the machine. 
- Figure 16 shows the result of the construction of the hybrid router-laser machine without the protection walls and in figure 17 with the complete assembly.

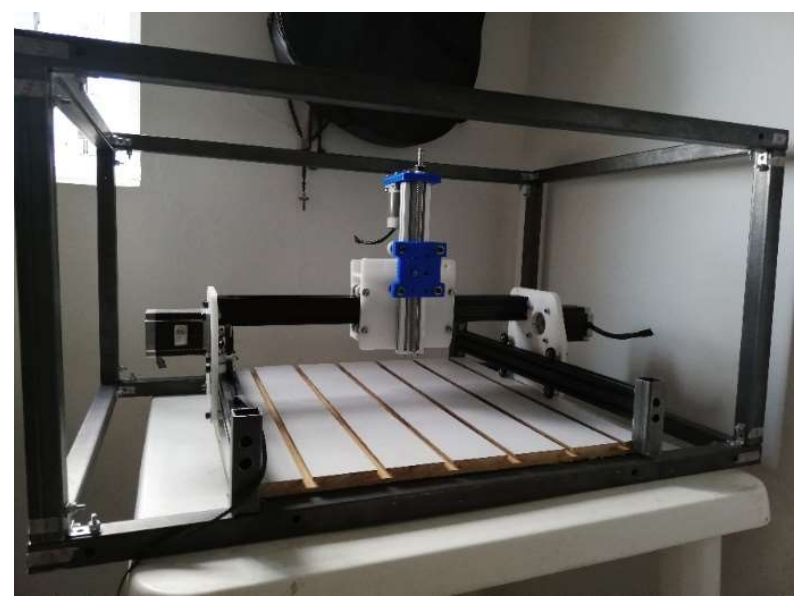

Figure 16: Hybrid machine without protective walls.

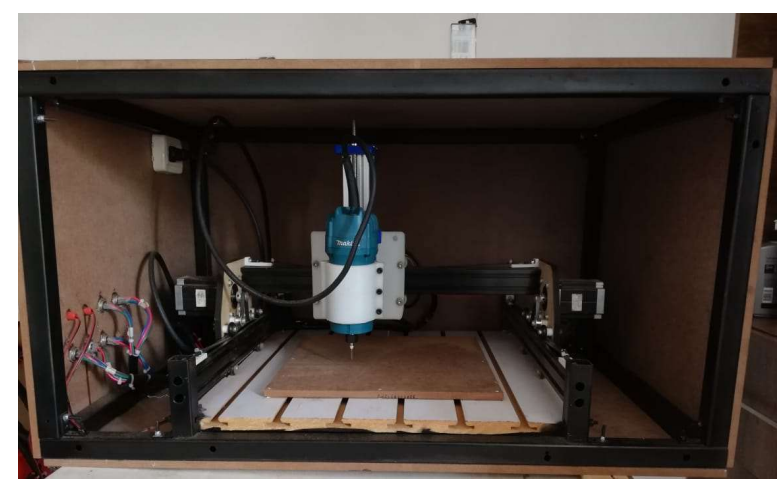

Figure 17: Hybrid machine with protective walls.

\section{CONCLUSIONS}

After conducting the corresponding evaluations, this type of design is highly recommended for desktop equipment in the $\mathrm{CNC}$ field. If a component is damaged, it can be replaced immediately with low prices.

It is recommended to use CAD design software of your choice in order to observe the design before its construction to avoid overhead, waste of material and money.

It is concluded that a tool consists of two or more simple machines or artifacts, so that simple machines are usually used in a certain combination, as components of more complex machines.

With this article we have learned about three simple mechanisms, the transmission of movement, the use of CAD software and the movement in three XYZ coordinate axes, at the same time of their operation and their usefulness in today's life.

\section{REFERENCES}

1. Transmission belts. (nd). Retrieved February 20, 2020, from https://ingemecanica.com/tutorialsemanal/tutorialn121.html

2. Cubides, R., Carlos, L., \& Heredia, S. (2009). Machining Prototype For Manufacture Of Printed Circuits In Baquelas. 
3. Daza, U., \& Luengas, S. (2016). CNC router applied to the development of PCB's. Daza, U., \& Luengas, S. (2016). CNC Router Applied to the Development of PCB's. $86 . \quad$ Retrieved from Http://Tesis.Ipn.Mx/Bitstream/Handle/123456789/21812/Tesis_URDM_SLZ.Pdf?Sequence=1\&isAllowed=y, 86. http://tesis.ipn.mx/bitstream/handle/123456789/21812/thesis_URDM_SLZ.pdf? Sequence $=1 \&$ isAllowed $=y$

4. García, M., \& Zamora, R. (2014). Design and manufacture of a 3-axis CNC milling machine for PCB machining with open development platforms. Universidad Politécnica de Cartagena., CNC Arduino., 77. http://repositorio.bib.upct.es/dspace/bitstream/10317/4393/7/tfg491.pdf

5. Hernández, CH, Rodríguez, RM, Manuel, B., \& Contreras, G. (2014). Design, construction and testing of a computer numerical control (CNC) machine for milling and drilling phenolic plates. 108, 1148-1169.

6. History of laser technology | Materials processing by laser es-us. (nd). Retrieved May 2, 2020, from https://www.ulsinc.com/es/conocer/historia-del-laser

7. Ball screw $\mid[T H K||$ MEXICO]. (nd). Retrieved February 19, 2020, from https://www.thk.com/?q=mexico/node/7517

8. Trapezoidal threaded spindle TR8x1.5 | MakerShopBCN. (nd). Retrieved February 23, 2020, from https://makershopbcn.com/en/product/trapezoidal-threaded-spindle-tr8x1-5-right

9. León, P., Aguilar, D., Maldonado, F., Vargas, N., \& Fernández, C. (2016). Foamy CNC laser cutting machine. 2016 IEEE International Conference on Automática (ICA-ACCA), 1-6. https://doi.org/10.1109/ICA-ACCA.2016.7778459

10. New DIY CNC - FRT_CNC-Finishing the Assembly - Mr. Ferrete's Website. (nd). Retrieved February 22, 2020, from http://srferrete.es/nueva-cnc-diy-frt_cnc-terminando-el-montaje

11. Santa, F., Ia, MAR, \& Anica, MEC (nd). DE Y CONSTRUCCI ON DESENO Summary. 